\title{
LA CIUDAD DE ITUZAINGÓ, ANTES Y DESPUÉS DE LA REPRESA HIDROELÉCTRICA YACYRETÁ-APIPÉ. PROCESO DE URBANIZACIÓN Y DISTRIBUCIÓN DE LOS GRUPOS SOCIALES: UNIDAD O FRAGMENTACIÓN
}

María V. VALENZUELA

toiavalenzuela@hotmail.com

Codirectora del Centro de Estudios Históricos, Arquitectónicos y Urbanos (CEHAU), FAU-UNNE. JTP de Arquitectura V, UPC, FAU-UNNE. Profesora libre a cargo de Arquitectura Paisajista, FAU-UNNE.

Palabras Clave: Proceso de urbanización; adaptación social; transformación territorial.

Keywords: Urbanizing process, social adaptation, territorial transformation

\section{RESUMEN}

Este trabajo se propone identificar y caracterizar las transformaciones urbanas y sus consecuencias en el ámbito social y cultural, vistas ambas como procesos concomitantes y simultáneos, a partir de la radicación de la obra de la represa Yacyretá-Apipé, en un pequeño pueblo de economía y tradición ganaderas. Se indaga sobre las variables referidas a la intervención del Estado y sobre sus consecuencias en el ámbito socio-urbano, teniendo en cuenta que los nuevos conjuntos habitacionales fueron concebidos con criterios arquitectónicos y urbanos de vanguardia y fueron asiento de grupos sociales migrantes heterogéneos, con intereses socioculturales y económicos diversos y claramente diferentes de los locales.

\begin{abstract}
This paper aims to identify and characterize urban transformations and their consequences in the social and cultural sphere, seen as concurrent processes, from the setting-up of the Yacyretá-Apipé dam, in a small village of traditional livestock economy. It explores the variables related to the State intervention and its impact on the socio-urban areas, considering that new housing projects were conceived with architectural and urban vanguard criteria were seat social groups migrant heterogeneous, with interest sociocultural and economic diverse and clearly different from the premises.
\end{abstract}




\section{OBJETIVOS}

- Indagar sobre el impacto de una gran obra de infraestructura en el tejido socio-espacial de Ituzaingó, vistos como procesos concomitantes y simultáneos.

- Identificar los mecanismos de adaptación que fueron surgiendo en el tiempo.

\section{INTRODUCCIÓN}

Este trabajo se propone identificar y caracterizar las transformaciones urbanas y sus consecuencias en el ámbito social a partir de la radicación de la obra de la represa Yacyretá-Apipé en un pequeño pueblo de aproximadamente 4000 habitantes, históricamente ganadero, en cuanto al dramático proceso de urbanización y consecuente producción de espacio urbano, con la incorporación de grupos sociales de características e intereses diferentes de los de la tranquila vida pueblerina.

Teniendo en cuenta que se trata de la obra hidroeléctrica más importante de la Argentina, nos preguntamos ¿cómo impacta en los medios social y urbano, vistos como procesos concomitantes y simultáneos, esta obra estatal de alcance nacional, de escala monumental, que conlleva la incorporación masiva de grupos sociales migrantes, distribuidos en nuevos espacios urbanos, que fueron adosados en forma imperativa a una traza urbana antigua y escasamente consolidada, sin buscar formas claras de relacionamiento social y urbano?

Otras preguntas que guiaron el estudio fueron las siguientes: ¿en qué medida se han modificado los modos de vida de la población ituzaingueña con la construcción de los conjuntos habitacionales y equipamientos de la Entidad Binacional YacyretáApipé (EBY)?; y si fue así, ¿se produjeron mejoras en las condiciones de vida urbana y social de la localidad?; ¿ha fomentado el Estado la integración social a través del planeamiento urbano de las nuevas infraestructuras con la creación de ámbitos que propicien el relacionamiento social?; ¿se ha generado, a través del tiempo, una sociedad integrada o persisten las asimetrías?; ¿cuáles son las formas de relacionamiento de la entidad ejecutora EBY (Entidad Binacional Yacyretá), con la comunidad de Ituzaingó?; ¿intentó la planificación urbana del Estado lograr una fusión entre el pueblo viejo y el pueblo nuevo?

Toda obra de infraestructura de gran escala, advierte CATULLO (2014), produce una serie de consecuencias de diversa índole -ecológicas, paisajísticas, ambientales, demográficas, culturales, sociales, económicas, entre muchas otras- en el territorio donde se asienta, y su dimensión dependerá de la situación previa del territorio, su grado de desarrollo, de fragilidad, etc., y en qué medida se la evalúa en el momento de la elaboración del proyecto. Es decir, si el proyecto de gran escala contempla en su complejidad, o a partir de una visión multidimensional, la situación del territorio que será afectado (CATULLO, 2014).

En el caso de estudio, la represa argentinoparaguaya Yacyretá-Apipé requirió resolver el alojamiento de una gran cantidad de personas para la construcción de la represa en un sitio antes ocupado por productores rurales que debieron ser relocalizados, vecino a un pueblo de baja densidad y escaso desarrollo económico. Una situación que no fue suficientemente evaluada y dimensionada en toda su complejidad. Aun así, mejor suerte corrieron los ituzaingueños que los habitantes de Federación, según explica CATULLO (2014), quienes debieron ser relocalizados y reasentados de manera arbitraria, dejando su pasado urbano, barrial y vecinal bajo las aguas del embalse de la represa binacional uruguayo-argentina de Salto Grande (CATULLO, 2014). 
“...la represa argentino-paraguaya Yacyretá-Apipé requirió resolver el alojamiento de una gran cantidad de personas para la construcción de la represa en un sitio antes ocupado por productores rurales que debieron ser relocalizados..."

La represa que nos ocupa fue construida sobre el río Alto Paraná en el extremo nordeste de la provincia de Corrientes, en el sector correspondiente al Departamento Ituzaingó, donde el paisaje fluvial comenzaba a delinearse, luego de abandonar la situación de encajonamiento a causa de las serranías misioneras y paraguayas, con un curso más abierto y un cauce entrelazado entre numerosas islas y bancos de arena, con afloramientos rocosos y desniveles que aceleraban las aguas y dificultaban la navegación (VALENZUELA, 2014).

\section{Antes de la represa}

El paisaje estaba definido por un angosto albardón arenoso que se desarrollaba a lo largo del río Paraná, que estaba atravesado por arroyos que generaban profundos tajos, llamados zanjones. Hacia el río, el albardón caía a pique formando altas barrancas, muy erosionables y cubiertas de vegetación (selva en galería). El río, en este tramo, presentaba desniveles naturales que en bajante formaban saltos de 3 a 5 metros de altura y afloramientos de las rocas basálticas que formaban parte de su lecho, correspondientes a la formación geológica Serra Geral, y generaban los llamados "Rápidos de Apipé". Con el cierre de las compuertas en agosto de 1994, los rápidos, junto a dos de las islas de mayor tamaño - Yacyretá y Talavera- quedaron sepultados bajo más de veinte metros de agua ${ }^{1}$ y con ellos, un histórico y emblemático paisaje.

El científico francés MARTíN DE MOUSSY (1856) se refirió al lugar de la siguiente manera: "bien encajonado y con riberas generalmente elevadas, cubiertas de grandes bosques, solo tiene pequeñas islas rocosas, salvo dos grandes de Apipé y Yauretá [Yacyretá] separadas entre sí por un canal estrecho. Cuando las aguas bajan

1 http://argentinainvestiga.edu.ar/diario_virtual. numerosos escollos se manifiestan y entre las islas de Apipé y la ribera correntina un arrecife divide en dos el lecho del río formando un rápido llamado Salto de Apipé. Ese mismo arrecife produce del otro lado de la isla Yauretá [Yacyretá], el salto de Areguá [Aña-Cuá], más elevado que el de la izquierda, solo puede ser franqueado por embarcaciones en tiempos de creciente". 2

En este paraje, cercano a otro sitio emblemático del entorno por su valor histórico conocido como "Tranquera de Loreto"3, paso controlado que atravesaba el zanjón homónimo del Camino Real Jesuítico, se funda el pueblo de Ituzaingó, a través de la gestión realizada por un ex miliciano de Garibaldi, de origen italiano, llamado Bernardino Valle, acompañado de otros dos vecinos, Francisco López y Juan Rivera, quienes convencieron al gobernador Lagraña sobre la necesidad de la creación de un pueblo, que sería estratégico para la avanzada española, en aquel sitio disputado largamente por paraguayos, brasileños y misioneros (ley promulgada el 24 de febrero de 1864). El comerciante italiano, luego de la mensura y amojonamiento del pueblo, se estableció con una casa de negocios al borde del río, cercana al puerto (LÓPEZ BREARD, 2001).

El puerto fue el principal motor económico para la conformación del pueblo, ya que, aparte del comercio de carne y sus derivados, era incidente la actividad generada como lugar obligado de desembarco de gente en tránsito hacia los pueblos misioneros, que provocó que se desarrollara una serie de servicios para ellos, como pistas de baile, almacenes, casas de comida, entre otros (LÓPEZ BREARD, 2001).

2 MARTín DE MOUSSY, 1856: 103, Citado en LEVINTON, N., 2007 p. 107.

3 Tranquera de Loreto: Punto de acceso a la estancia jesuítico-guaraní

"Santa María" y sitio de trinchera de varias contiendas en la defensa del territorio de las Misiones. También fue utilizado como límite del avance español. 
El trazado del pueblo respondió al clásico damero de las Leyes de Indias: una cuadrícula ortogonal de manzanas de $100 \times 100$, como la mayoría de las ciudades americanas, la que se fue consolidando y caracterizando según los distintos roles económicos que se sucedieron en el tiempo. La actividad portuaria marcó el primer momento del desarrollo urbano, "por lo tanto, dos calles paralelas al río, Bernandino Valle y Francisco López, y la calle de acceso, Centenario, se constituyeron en las franjas principales de desarrollo urbano durante el período del modelo agro-exportador (1864-1930), y el Centro Institucional o Cívico se ubicaría también en estas franjas: la sede del Edificio Municipal, el Correo, la Prefectura, la Escuela, el Banco Provincia, entre otros" (S. NEGRETTE-VALENZUELA, 2011). La iglesia matriz, San Juan Bautista, sin embargo, se emplazó frente a la plaza principal General San Martín, junto a viviendas de escasa calidad arquitectónica y constructiva (arquitectura vernácula) donde, ya a fines del siglo $X X$, se sumaron otros edificios institucionales como el Centro Cultural y el Museo Antropológico, conformando un nodo de desarrollo urbano más tardío. Otro nodo se constituyó en el entorno de la plaza Centenario, ubicada sobre la calle homónima, en función del acceso principal a la ciudad.

El área central era la más consolidada, con servicios de infraestructura, alumbrado y pavimento. Estaba habitada por los sectores medios y altos. Las familias más acomodadas, con recursos económicos provenientes de la actividad ganadera - tipo de explotación mediana de ganadería extensiva-, se localizaron a lo largo de las calles Francisco López, Buenos Aires o en torno de la plaza Centenario, donde aparecen las viviendas más importantes. Sin embargo, no se identificaban barrios dentro de la trama urbana antigua, en el sentido definido por PIERRE GEORGE, quien lo sitúa como una unidad significativa e identitaria (CATULLO, 2014). Todo el pueblo compartía una misma identidad ligada al pasado prehispánico guaraní y, posteriormente, a la cultura pecuaria tradicional de herencia española y a una fuerte religiosidad.

La planta urbana antigua no se vinculaba con el río de manera franca y definida, por lo tanto, este sector no atraía el interés como lugar de reunión y paseo. La vida social y los principales acontecimientos socio-urbanos (fiestas patrias, eventos culturales y religiosos) se llevaban a cabo en torno de la plaza San Martín. Su centro cívico y otros equipamientos institucionales, así como las principales viviendas se volcaron hacia los ejes mencionados o hacia las plazas, como sucedió en muchas otras ciudades ribereñas, quizás por temor a las inundaciones o a la erosión fluvial. Solo algunas casas de condición precaria fueron construidas sobre la barranca, en general, pertenecientes a pescadores u obreros portuarios.

El paisaje urbano era heterogéneo, con distintos grados de consolidación y de baja densidad. Su arquitectura correspondía a distintos momentos históricos, por ejemplo: casas coloniales de galería, italianizantes, pintorescas con influencia brasileña, construidas sobre la línea municipal o retiradas, con abundante vegetación inserta en la trama, tanto en patios, en plazas como en calles (S. NEGRETTEVALENZUELA, 2011).

Con un pasado prehispánico guaraní, de grupos que vivían en las costas e islas del Paraná, luego jesuítico-guaraní, de estancias ganaderas que luego pasaron a manos españolas, se fue forjando una idiosincrasia de gran tradición cultural ligada a las actividades rurales y religiosas, con vestigios de la cultura originaria que se aprecia, aún hoy, en la gastronomía, con el chipá y el mbaipú, o en uso de vocablos provenientes de la toponimia guaraní que identifican lugares, como Yacyretá (tierra de la luna), Apipé (lomada) o el mismo nombre con que se denominó al pueblo: Ituzaingó, cuyo significado es debatido por varios autores, pero 
"El paisaje urbano era heterogéneo, con distintos grados de consolidación y de baja densidad. Su arquitectura correspondía a distintos momentos históricos..."

preferimos el que hace referencia a una leyenda local: ¡|túozaingóoina! (Itú, colgado se está moviendo - movimiento pendular-), referido al cacique Itú (LÓPEZ BREARD, 2001: 87).

\section{Inicio del cambio: las obras de la Entidad Binacional Yacyretá (EBY)}

El pueblo, si bien tuvo un incipiente desarrollo, a mediados del siglo XX se estancó debido a la merma del tránsito fluvial y a una economía basada principalmente en la actividad pecuaria, cuyos procesos son menos dinámicos que la agricultura. El crecimiento poblacional alcanzó un máximo en la década del 40 del siglo XX; luego este proceso se revirtió debido al éxodo migratorio hacia los centros en crecimiento propulsados por la incipiente industria nacional que se desarrolló como consecuencia de la sustitución de importaciones provocada por la Segunda Guerra Mundial (LUCIANO, 2013). Esta tendencia continuó hasta que el Proyecto Yacyretá-Apipé comenzó a vislumbrarse.

En 1970 la localidad contaba con 3421 habitantes, y una década después se habían incorporado 5215 personas al ejido municipal (8636 habitantes, según Censo 1980). Numerosas familias llegaron desde distintas zonas del país en busca de oportunidades laborales, por motivación propia, antes del inicio formal de las obras. Además, se sumaron los relocalizados de las islas y otros afectados por el embalse. Por ello, la planta urbana comenzó a saturarse, al igual que la provisión de servicios, y se agudizó el problema de precariedad de algunos sectores: solo el $41,8 \%$ de las casas tenía baño instalado, indicador que da cuenta del bajo nivel socioeconómico de la población en aquel momento. Además, la tasa de mortalidad infantil era elevada debido a una infraestructura sanitaria insuficiente (LEVINTON, 2007).
En 1991, unos años después del inicio de las obras, la población llegó a duplicarse con un total de 16.995 habitantes. En dos décadas la población se quintuplicó pasando de los 3421 a los 16.995 habitantes. En las décadas posteriores, sin embargo, el crecimiento mostró una desaceleración notable, dado que en el Censo de 2001 se registró un aumento de 2060 habitantes y en 2010 solo de 364 habitantes. ${ }^{4}$

El proyecto hidroeléctrico se efectiviza en 1974 con la firma del Tratado de Yacyretá. Un año después, se decide el emplazamiento de los conjuntos habitacionales -Villa Permanente y Villa Transitoria-, para la gente afectada a la obra y a la EBY en ambos países (LEVINTON, 2007: 184). Sin embargo, tanto los afectados por el embalse como los habitantes de las islas y bordes costeros quedaron fuera de los presupuestos de la obra, y su relocalización fue resuelta por el Estado provincial con dos barrios de viviendas -B. ${ }^{\circ} 50$ y 70 viviendas-, mucho más modestas, ubicados en la periferia del pueblo, fuera del ámbito territorial de EBY.

La construcción de la represa hidroeléctrica, propiamente dicha, y la central se inició en 1983 con la obra civil principal. Once años después, comenzó a brindar energía con la instalación de las primeras turbinas (1994); en mayo de 1998 culminaron las obras con la puesta en marcha de la última turbina. En 2011 se elevó la cota de inundación del embalse a 83 m, lo que requirió una gran inversión en obras complementarias en las ciudades de Posadas (Argentina) y Encarnación (Paraguay).

4 Este dato responde a una proyección realizada sobre la base de la hipótesis de que la relación entre población rural y urbana del departamento se mantenía a los niveles del año 2001, ya que los datos censales de 2010 solo fueron publicados a nivel departamental. Plan Estratégico de Ordenamiento Territorial de Municipio de Ituzaingó, IPUR-UNNE CFI. 
La decisión de construir el nuevo conjunto habitacional —Villa Permanente, Villa Transitoria, B. ${ }^{\circ} 27$, viviendas para directivos y residencias jerárquicas-, contiguo al pueblo, al ejido urbano, respondió a la intención de que en el futuro formara parte del mismo conjunto urbanístico y, por otra parte, para favorecer la conectividad con la obra y usar los escasos servicios que ofrecía el pueblo. Los nuevos barrios fueron dotados de equipamientos, infraestructura y servicios completos, arborización de calles y avenidas, generosos espacios públicos, etc., con un diseño urbano moderno y eficiente, en el que se tuvieron en cuenta criterios ambientales y paisajísticos innovadores para la época, como control climático destinado a atenuar el asoleamiento de calles y viviendas y favorecer la circulación de brisas para disipar los efectos de las altas temperaturas estivales. También se buscó propiciar la buena relación ciudad-río, factor este que el pueblo no había resuelto aún.

Para el proyecto de la nueva urbanización se convocó al equipo de proyecto urbano-arquitectónico liderado por los arquitectos Juan M. Llauró, José Urgell, Eduardo Bustillo, Jorge Moscatto, Rolando Schere, que propusieron una traza de acuerdo con criterios de la vanguardia setentista, con manzanas alargadas, amplios bulevares y una gran superficie destinada al esparcimiento, tanto barriales como vecinales (uno en cada manzana), de distinto tamaño y ubicación. Los edificios fueron adecuados climáticamente con ventilación cruzada y sobretecho o techo sombra para atemperar las altas temperaturas estivales. La mayoría de las viviendas contaba con una generosa superficie destinada a jardines.

El proyecto original contemplaba una serie de medidas urbanísticas destinadas a la integración de la nueva pieza urbana con el pueblo; por ejemplo: equipamientos de uso común y servicios, como la hostería y equipamientos educativos; un trazado que daba continuidad a las calles y un paseo costero, coincidente con las obras de contención de la barranca, que sería destinado al uso público (N. ${ }^{\circ} 12$ en Fig. 1). Sin embargo, se realizaron cambios durante la construcción de la obra en desmedro de estas intenciones. En primer lugar, el paseo costero previsto para vincular, de forma franca y segura, a la ciudad con su borde ribereño nunca se construyó, solo se llevaron a cabo las obras de contención de la barranca, tanto hacia el río como hacia el zanjón. El paseo proyectado ofrecía una circulación peatonal a lo largo de la ribera del Paraná y del zanjón de Loreto e incorporaba el paseo "Los Pioneros" y otras perpendiculares destinadas a dar accesibilidad a la línea de ribera; su construcción hubiera significado la creación de un lugar de reunión y de paseo para la comunidad toda. Sin embargo, este borde quedó para uso exclusivo del Club Yacyretá.

En segundo lugar, la hostería (ver N.$^{\circ} 6$ en Fig. 1) que originalmente estaba ubicada en relación directa con la trama del pueblo, para que pudiera ser utilizada como un equipamiento de uso común, se ubicó finalmente en un sector apartado, en el interior de la nueva urbanización, y su uso quedó limitado a la exclusividad de la EBY (N. ${ }^{\circ}$ 7 en Fig. 2). En tercer lugar, se construyeron los barrios jerárquicos y las cinco viviendas destinadas a las autoridades, las que, por otra parte, según los estándares del pueblo, fueron consideradas "mansiones", en el terreno que había quedado como reserva en el proyecto original. Esto trajo aparejada una doble consecuencia negativa: por un lado, se dificultó el contacto de la ciudad con el zanjón Loreto y con el paseo "Los Pioneros" y, por otro, la cercanía de la construcción al borde del zanjón aceleró el deterioro ambiental de este.

Finalmente, y agudizando la situación de fragmentación, se construyó un cerco fuertemente custodiado que delimitaba la zona de obra, y con esto se efectivizó la segregación entre los nuevos y los viejos pobladores. LEVINTON (2007) afirma 


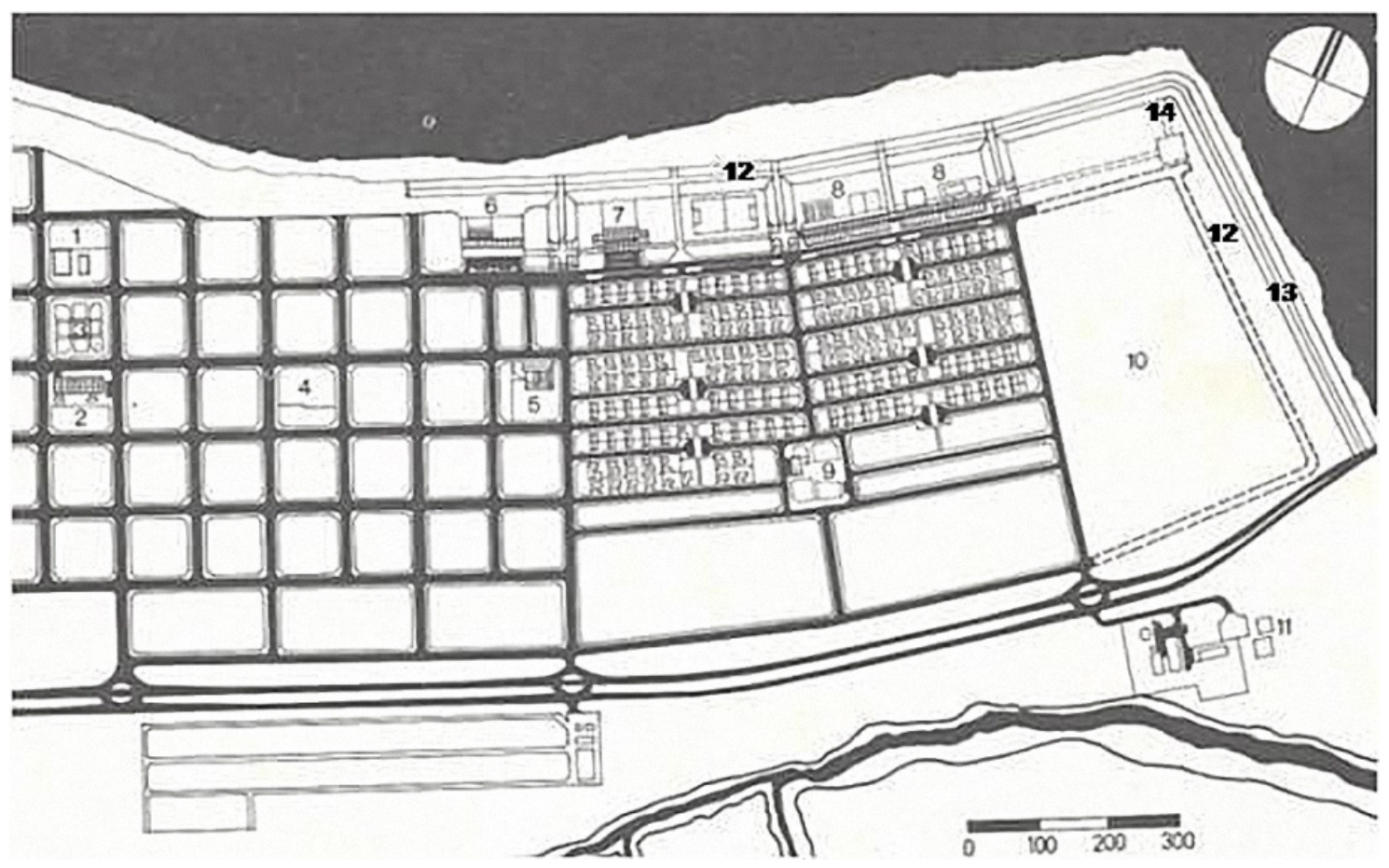

Fig. 1: Proyecto original (1975/76): 1. Centro parroquial. 2. Centro Cultural. 3. Remodelación plaza San Martín. 4. Planta elevadora de líquidos cloacales. 5. Ampliación hospital. 6. Hostería. 7. Escuela. 8. Pabellón de alojamiento. 9. Guarderías. 10. Reserva. 11. Usina. 12. Consolidación de barranca y paseo Costero. 13. Zanjón de Loreto. 14. Lugar del paseo "Los Pioneros". Fuente: elab. propia sobre plano revista SUMMA N. ${ }^{\circ} 205-1984$.

que fue el Estado, durante el gobierno de facto, el que impuso esta serie de medidas (LEVINTON, 2007: 185).

Si bien se construyeron equipamientos para el uso del pueblo en el ejido urbano, en forma simultánea a los nuevos conjuntos habitacionales - por ejemplo, el Centro Cultural, emplazado frente a la plaza San Martín o la ampliación del Hospital Billinghust, para disminuir el impacto sociourbano-ambiental-, aunque fueron beneficiosos para la comunidad, no llegaron constituirse en ámbitos de integración social debido a razones que exceden a este trabajo.

A través de la comparación de los planos 1 y 2 (Fig. 1 y 2) registramos, aparte de las ya mencionadas, numerosas diferencias entre lo proyectado y lo que finalmente se construyó. En este sentido, hay que considerar varios elementos que dan cuenta de que las modificaciones realizadas durante la obra estaban destinadas a la "segregación" más que a la "integración". Para realizar esta afirmación nos apoyamos en el concepto de "segregación residencial" de M. CASTELLS, vista como la segregación en el marco de las ciudades, mencionada en el texto de RODRÍGUEZ MERKEL (2014), quien determina que esta existe solo "en aquellas situaciones en que la distancia social tiene una fuerte expresión espacial, y donde las distancias sociales se plantean no solo en términos de diferencia, sino de jerarquía. Dicho de otro modo, el concepto de segregación residencial se aplicaría — según CASTELLS - solo a casos donde la distribución desigual en el espacio involucra grupos que presentan desigualdades de estatus o jerarquía social" (RODRÍGUEZ MERKEL, 2014).

Dicho esto, no hay dudas de que estamos frente a este tipo de segregación, debido a que, justamente, la división espacial se asienta en las "desigualdades de estatus y jerarquía social", más que en las que pudieran resultar de los efectos del mercado inmobiliario, como ocurre frecuentemente en otros centros urbanos.

Así también, consideramos errónea la elección del sitio de implantación de los conjuntos habitacionales de EBY, debido a que se produjo una grave desvinculación del pueblo con su lugar histórico más importante y de referencia regional (el "Zanjón de Loreto ${ }^{5}$ y el Paseo "Los Pioneros ${ }^{6 "}$ ), como se mencionó anteriormente. Este sector, que en el proyecto original (Fig. 1) había quedado libre de construcción, como reserva para el libre acceso al zanjón y al paseo, luego se ocupó con los barrios para personal jerárquico. Esto tiene diversas consecuencias que consideramos abusivas

5 Zanja divisoria de la estancia "Santa María" —también utilizada como desagüe de las tierras bajas del Iberá-; posteriormente fue trinchera durante la guerra guaranítica y frontera de la expansión española hacia el este (VALENZUELA, 2009).

6 El nombre del paseo "Los Pioneros" fue dado en homenaje a los primeros estudiosos del río Paraná, ingenieros Gamberale y Mernoz, que estuvieron a cargo de la Dirección de Puertos de Buenos Aires, recorrieron este tramo y concluyeron con el estudio acerca de la posibilidad de construir sobre los rápidos de Apipé una obra de aprovechamiento hidroeléctrico. Fue declarado patrimonio histórico natural provincial. 


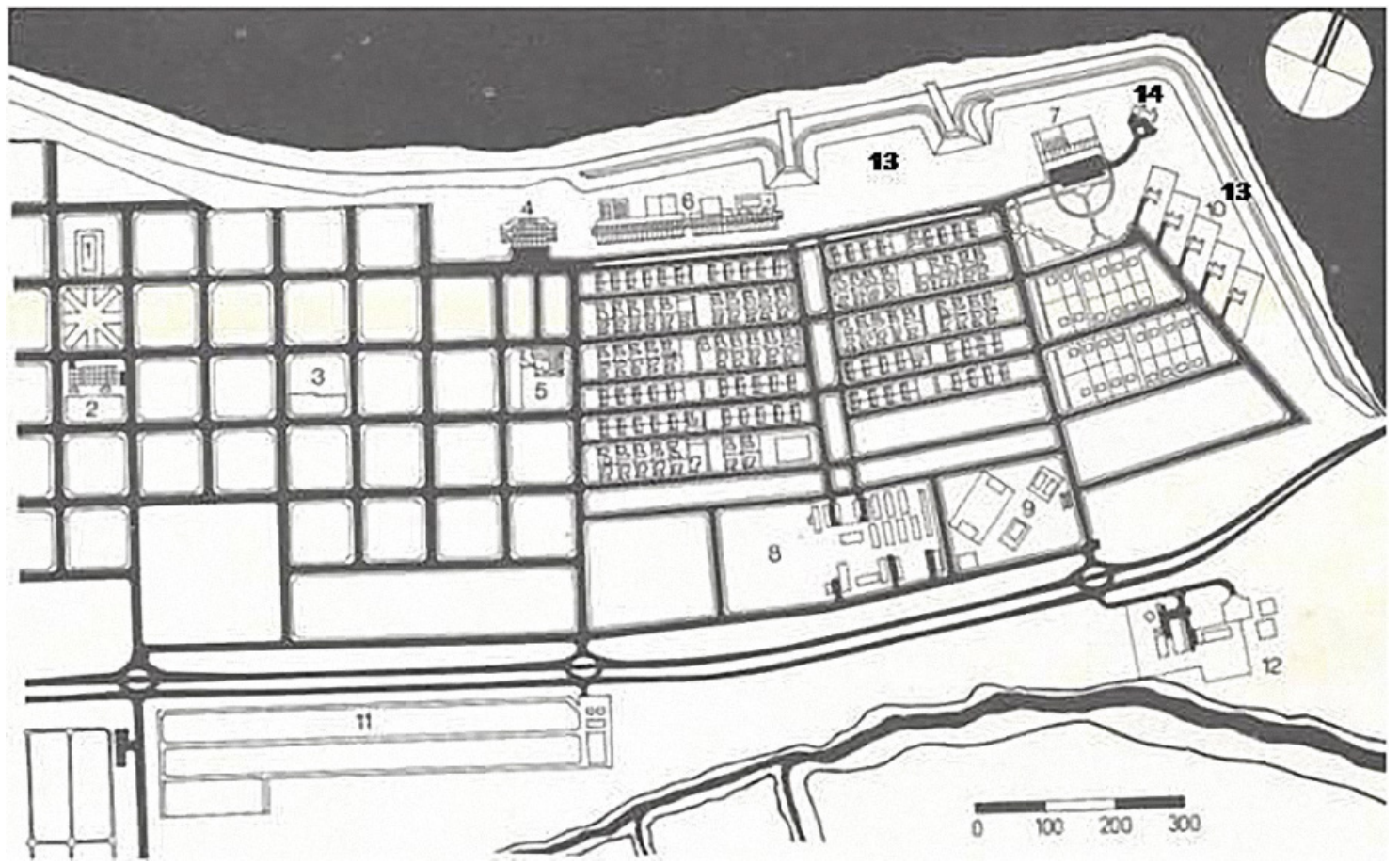

Fig. 2: Planta de conjunto construida (1982): 1. Iglesia. 2. Centro Cultural; 3. Planta elevadora cloacal. 4. Escuela; 5. Hospital. 6. Pabellón. 7. Hostería. 8. Área de oficinas. 9. Áreas deportivas. 10. Viviendas para autoridades y personal jerárquico (B. 28 viviendas). 11. Vivero. 12. Usina y planta potabilizadora de agua. 13. Talud de contención de la barranca; 14. Paseo "Los Pioneros". Fuente: elab. propia sobre plano Rev. SUMMA N. ${ }^{\circ} 205-1984$.

y arbitrarias: la no valorización de un lugar histórico altamente apreciado por el ituzaingueño; la desvinculación de este espacio del paseo cotidiano de los pobladores y la dificultad de acceso y recorrido del zanjón, que fue agravado, recientemente, por la construcción de un cerco que terminó por bloquearlo, y, por último, la apropiación de un espacio público de gran calidad paisajística para el beneficio de unos pocos.

Es evidente que, aunque el grupo proyectista de la urbanización tuviera las mejores intenciones de fomentar la integración social y minimizar el impacto sociourbano — con la salvedad de que es notorio el desconocimiento profundo del lugar puesto en evidencia al no haber sido contemplado el paseo "Los Pioneros" en el proyecto (Fig. 1)—, el Estado Nacional, con ciertas decisiones erróneas, no solo no ha fomentado la integración social y urbana a través del planeamiento urbano de las nuevas infraestructuras, sino que ha fomentado la fragmentación y la segregación. Así, se crearon espacios privados donde había una serie de equipamientos de alto nivel y telecomunicaciones de última generación solamente para uso de "ellos", como comenzaron a denominarlos los vecinos locales. Es decir que una parte de Ituzaingó era del Primer Mundo y estaba globalizada, mientras la otra seguía sumida en el retraso y la marginación.

El cerco divisorio, si bien fue construido para delimitar el espacio de obra, se convirtió en un símbolo de aguda fractura social debido a que permaneció varios años después de la finalización de aquella. En efecto, el "Muro de Berlín", como solían denominarlo los vecinos, fue parte del paisaje ituzaingueño por más de cinco años y quedó marcado, a fuego, en la memoria de la comunidad como un símbolo de la exclusión. Al respecto expresa LINS RIBEIRO que el plan significó: "la creación de dos Ituzaingó: uno, el histórico, el Ituzaingó pobre, representado por los correntinos mayormente contratados por el proyecto Yacyretá como trabajadores no calificados; el otro, el nuevo y poderoso Ituzaingó nacional e internacional" (LEVINTON, 2007: 187).

Pero no solo el cerco señalaba esta escisión. Los criterios urbanos y arquitectónicos con que fueron concebidos estos barrios eran diferentes de los del pueblo, cuya consideración como entorno inmediato, con sus características particulares urbanas y sociales, fue casi nula. En primer lugar, el amanzanamiento alargado o rectangular, aunque continuaba la linealidad del pueblo, fue concebido con un criterio diferente del de la unidad indiana de $100 \mathrm{~m} \times 100 \mathrm{~m}$ rodeada de calles con pulmones de manzana. Aquel fue planteado como unidades alagadas y angostas — de 400 m x 50 m-con espacios verdes a media longitud, sin pulmón de manzana y con distinta relación vivienda-acera urbana. Este tipo amanzanamiento aumenta la superficie de calles, pero la acera pública resulta angosta e incómoda para el tránsito peatonal. 


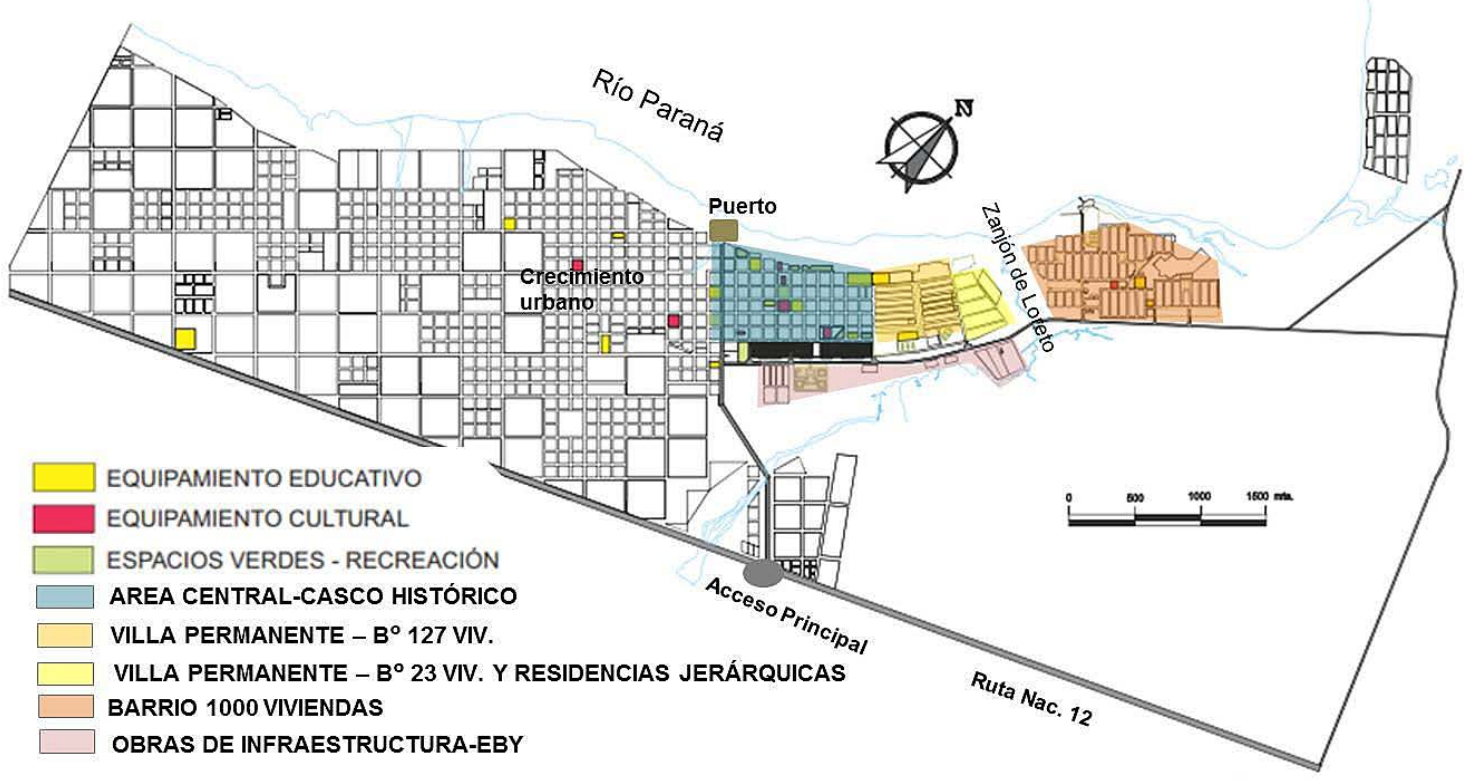

Fig. 3. Planta urbana de Ituzaingó. A la derecha los grupos habitacionales de EBY; a la izquierda la expansión urbana. Elaboración propia sobre base de Informe Programa Universidad en el Medio FAU-UNNE, 2011

El paisaje urbano resultante, homogéneo y discontinuo, no hacía referencia alguna al paisaje pueblerino.

En resumen, esta escisión eminentemente espacial tuvo sus consecuencias en la esfera social y generó un agudo contraste no solo urbano y arquitectónico, sino cultural, social y de clase en la pequeña comunidad acostumbrada a los ritmos e idiosincrasia rural. La revista SUMA (N. ${ }^{\circ} 205$, año 1974) alertaba sobre los posibles riesgos de impacto de esta experiencia de emplazamiento de grandes obras de infraestructura cercanas a poblaciones existentes, poco probada en la Argentina, y agregaba que aunque ya se había construido Salto Grande, era un caso diferente, que conllevó el traslado de la población de la antigua Federación y la refundación del pueblo en otro sitio, además de que no había transcurrido el tiempo suficiente para evaluar y arribar a conclusiones definitivas acerca de sus consecuencias socio-ambientales.

Estos profundos cambios socio-territoriales en el medio urbano suponen en términos de $M$. CASTELLS, la aparición de la ciudad dual definida como la "coexistencia espacial de un gran sector profesional y ejecutivo de clase media con una subclase urbana" (VALDÉS, s/f). CASTELLS se refiere, con la expresión "subclase urbana" a la clase más desfavorecida en la escala socioeconómica como consecuencia del desarrollo contradictorio de la nueva economía informacional, y la conflictiva apropiación de la ciudad por grupos sociales que comparten el mismo espacio mientras que son mundos aparte en términos de estilos y posición estructural en la sociedad (RODRÍGUEZ MERKEL, 2014). Este concepto de ciudad dual es asimilable a la situación que debió y debe atravesar la ciudad de Ituzaingó a partir de la radicación de EBY, con la salvedad de que mientras CASTELLS se refiere a las subclases como a las más desfavorecidas en la economía informacional, en este caso nos referimos a las que quedaron excluidas del gran movimiento económico y tecnológico acontecido en el mismo territorio.

La necesidad de división socio-espacial se plasmó, asimismo, en la urbanización nueva. La superficie ocupada por la EBY está dividida por un enorme y profundo zanjón, que es un sitio histórico de la época de ocupación de las estancias jesuíticas (Fig. 3). La existencia de este gran tajo favoreció la fragmentación dentro de la nueva ciudad: al este del zanjón, quedaron en el barrio Mil Viviendas, los obreros y personal de menor categoría y al oeste, y más cercano al pueblo, en la Villa Permanente, el personal jerárquico, los titulados y los técnicos especializados.

Aquí se comprueba con claridad lo que expresa DI VIRGILIO-HEREDIA (s/f) sobre que las clases sociales, aun dentro de un mismo emprendimiento o empresa, "operan como un sistema de clasificación que permite establecer diferencias en los grupos sociales en términos de la dotación de recursos". La división de clases está basada, en este caso, en los niveles jerárquicos. Los menos favorecidos estaban ubicados más alejados del pueblo, en una localización periférica, dividida por el zanjón, solo vinculados por un angosto puente vehicular. 
Aunque contaban con los servicios y equipamientos necesarios para cubrir sus necesidades cotidianas, como un centro comercial, una escuela primaria y secundaria, un club deportivo con canchas y piscina, plazas, estaban aislados de un contacto social más amplio.

En conclusión, esta "nueva ciudad" en realidad no es más que un conjunto de barrios, bien diferenciados según categorías establecidas por el Estado, basadas en la jerarquía. Con la finalización de las obras de la EBY hubo un recambio poblacional: los técnicos e ingenieros extranjeros volvieron a sus lugares de origen y fueron reemplazados por otros expertos en transporte de energía. Muchos de los obreros se quedaron en las casas asignadas, aun sin trabajo, por no atravesar una nueva e incierta mudanza, sin ofertas de trabajo en otro sitio, sumado a que sus hijos ya estaban integrados y estudiando. En el caso de las Mil Viviendas o barrio Obrero se les ofreció la oportunidad de adquirir sus viviendas a través de un plan de pago muy conveniente.

Con el tiempo, y hace no más de quince años, los trabajadores de EBY, algunos de ellos ya jubilados, llevan más de treinta años en la localidad, que con anterioridad dirigían sus inversiones hacia otras locaciones, viraron sus expectativas hacia la antigua estructura de Ituzaingó provocando una paulatina movilización de la economía local. Esto motivó el inicio de la creación de lazos con la comunidad local. Esta tendencia se dio de manera natural, no hubo intervención del Estado, fue solo motivado por las oportunidades que ofrece el lugar en cuanto a su potencial paisajístico playas, ecoturismo-. Y aquí encontramos uno de los factores de vinculación entre la población nativa y la inmigrante ${ }^{7}$.

7 Manifestado por dos vecinos de la Villa Permanente, ambos profesionales, uno de ellos vinculado con la industria energética y el otro trabaja en educación secundaria.
Sin embargo, aún hoy persiste la dificultad en el relacionamiento. Muchos lugareños iniciaron pequeños emprendimientos económicos para dar servicio a las familias relacionadas con la EBY, o lo que es lo mismo, a los sectores de mayor poder adquisitivo; por ejemplo, comercios de marcas de indumentaria reconocidas, gastronomía, supermercados, hotelería, etc., pero se quejan de que aquellos no utilizan sus servicios con la expresión "esa gente no consume acá", como lo enunció un vecino apodado $\mathrm{Napo}^{8}$, lo que se interpreta como menosprecio o falta de confianza.

Una sociedad sustentable, dice R. PESCI (2006), "requiere de la participación de todos los sectores, con esfuerzos propios y ayudas mutuas"; la condición humana es imperfecta y tiende siempre a la entropía. La desconfianza, producto de los conflictos sociales basados en la trasgresión al contrato social, ha generado formas de ocupación del territorio, tipologías urbanísticas -me refiero a los countrys, entre otrosque vuelven cada vez más insustentables las relaciones de la sociedad en el territorio.

En cuanto a la relación socio-territorial, los habitantes locales tienen un arraigo en su territorio, en su paisaje, que da cuenta de su pasado y que refrenda sus costumbres. Esta condición se vio amenazada por la invasión cultural de la avalancha de inmigración, tanto extranjera como de otras provincias, que duplicó sobradamente la población local; por tanto, los ituzaingueños vieron diluirse o debilitarse su acervo cultural y su idiosincrasia. Por ello, cuando lograron ser conscientes y hacerse cargo de esta situación, a principios de los 2000, pusieron el marcha el rescate del "ser local" con la puesta en valor y la visibilización tanto de la cultura guaraní como de la gauchesca, a través de la restauración

8 Luis Napoleón Berestain, ingeniero agrónomo nacido en Ituzaingó, ex concejal del Partido Autonomista, empleado de la EBY como especialista en fauna ictícola, por un corto período. 
"Los nuevos barrios resultaron extraños para el habitante nativo, desde la propuesta arquitectónica urbanística, debido a que estos no tuvieron una intención decidida de contextualización social y cultural."

del Club Social, la apertura de los museos de Campo y de la Ciudad y el Museo Antropológico, donde están expuestos los elementos de la cultura guaraní rescatados durante los trabajos arqueológicos realizados con anterioridad al inicio de la obra. Estas y otras conclusiones fueron extraídas de entrevistas realizadas a referentes locales, tanto de los habitantes originarios como de migrantes, que llevan más de quince años radicados en la ciudad.

Los nuevos barrios resultaron extraños para el habitante nativo, desde la propuesta arquitectónica urbanística, debido a que estos-aparte de lo ya mencionado- no tuvieron una intención decidida de contextualización social y cultural. Por ello, los ituzaingueños, por décadas, excluyeron estos barrios de su imaginario urbano, no se identificaron con sus espacios; para ellos, ese lado de la ciudad siempre formó parte de "la otra Ituzaingó", y viceversa, los nuevos habitantes no se reconocieron como parte de la población local.

Al intentar elucidar las razones de esta situación nos encontramos, como primera cuestión, con que los barrios son propiedad de la entidad, situación que se mantiene aún hoy en algunos de ellos, como la Villa Permanente, el barrio 28 Viviendas y las cinco residencias para autoridades. Por ello, los habitantes de los barrios EBY saben que son temporales, se reconocen como tales, serán usuarios de las viviendas en tanto continúen en relación laboral con la entidad, su empleador directo o indirecto - referido a empresas de servicios relacionados con la actividad hidroeléctrica- Al no poder adquirir sus viviendas, no se genera el sentimiento de arraigo. Frente a esta situación, estos moradores transitorios -la mayoría de ellos con altos ingresos - optaron por adquirir propiedades, a modo de inversión, para emprendimientos inmobiliarios (departamentos, locales comerciales) o turísticos (conjunto de cabañas y servicios de pesca) en las periferias del lado oeste de la ciudad, hacia donde esta ofrece su alternativa actual de crecimiento. Por tanto, los "de allá" y los "de acá", o los locales y los foráneos, pueden identificarse como actores sociales diferenciados, debido a que son grupos con características distintas; por ejemplo, respecto de la relación con el espacio físico, de los intereses y capacidad económica, de la cultura y la idiosincrasia, del nivel de capacitación, entre otros.

Haciendo un repaso por la bibliografía que investiga la temática de segregación social y habitacional en la ciudades latinoamericanas, nos encontramos que esta responde a factores fundamentalmente económicos derivados del sistema capitalista o en otros casos étnicos o religiosos, por ejemplo, la (re) definición del concepto de segregación habitacional de RODRÍGUEZ MERKEL (2014) como "el proceso mediante la cual los grupos sociales de mayor poder restringen, condicionan o limitan - a través de distintos mecanismos, y de manera no siempre consciente e intencional- las oportunidades de acceso al suelo urbano a los grupos de menor poder, resultando en su distribución desigual u otras formas de separación en el espacio físico de la ciudad". Nuestro caso tiene características particulares, por lo que no pueden ser asimiladas a conceptualizaciones como esta, en la que no se contemplan la situación de transitoriedad de los habitantes o de la incapacidad de adquirir el bien mueble.

En cuanto a esto último, la nueva población o población itinerante tenía y sigue teniendo un nivel de educación superior, universitaria o terciaria, a diferencia de los pobladores nativos, que solo alcanzaban el nivel secundario, salvo excepciones de personas que han asistido a centros de estudios fuera de la localidad y han regresado. Entonces, 
nos preguntamos si, con el transcurso del tiempo se ha generado una sociedad integrada, que involucre a todos los actores sociales o persisten los grupos sectarios. Si bien perduran algunas asimetrías, como los niveles de ingreso y, por tanto, de vida, muchos opinan que desde hace aproximadamente quince años, debido a que se han realizado uniones conyugales entre personas de ambos sectores y nuevas inversiones y relaciones laborales destinadas al pueblo, las asimetrías han disminuido y las distancias se han acortado, aunque las desigualdades principalmente en el aspecto económico continúan.

Las desigualdades socioculturales se perciben claramente hoy, no hay más que interrogar a los vecinos que atravesaron ese período, quienes manifiestan que se sintieron excluidos de "la gran oportunidad" esperada por tanto tiempo. Así se generó una gran desigualdad social con respecto al acceso a determinados bienes y servicios, que se tradujo en un desequilibrio social áspero pero silencioso. Como resultante, se produjo un rechazo encubierto a todo lo concerniente a la EBY, que podría haber sido interpretado como desinterés. Esto dificultó la integración, el intercambio de bienes y saberes que hubiera resultado fundamental para el desarrollo local. Los vecinos optaron por aferrarse a su idiosincrasia ganadera, de hombres de campo, a sus costumbres, a sus ritos religiosos, a su andar cansino de pueblo chico, sin intentar incluir la globalidad, la interculturalidad, la diversidad.

\section{REFLEXIONES FINALES}

El pueblo de Ituzaingó atravesó, a partir de la construcción de la represa hidroeléctrica, un abrupto proceso de urbanización con características particularmente complejas, que no solo tuvo repercusiones en el crecimiento desigual de la planta urbana, sino en su tejido social, que se vio seriamente alterado por la llegada de 30.000 trabajadores de diferente clase social, nivel socioeconómico, nivel de especialización y procedencia — muchos de ellos eran extranjeros-, con sus familias. Estos conformaban un grupo muy heterogéneo desde lo social, lo cultural, lo educativo, cuyas expectativas estaban centradas únicamente en el trabajo, el que sería temporario, es decir, con fecha de finalización cierta o incierta, pero definitiva. Por ello, el trabajador también se vio como un habitante temporario del espacio y no manifestó interés alguno por la integración social ni espacial. Por otra parte, el habitante local, agobiado por la desigualdad, la marcada diferencia de calidad de vida o la inexistencia de intereses comunes, se vio obligado a replegarse en el pueblo y minimizar el contacto. El Estado no propició la relación, el intercambio, es más: la dificultó creando el símbolo de la fragmentación, de la desigualdad, de la no inclusión con el emblemático "cerco con garita de seguridad", como lo describen algunos vecinos, o el "Muro de Berlín" según otros.

Por ello, estos dos grupos sociales, actores de un mismo espacio, no intercambiaban ni hacían esfuerzo alguno para el relacionamiento. Esta situación comenzó a cambiar, según manifiestan los propios actores de ambos sectores, a partir de quince años atrás, cuando un sector de "esa gente", según el decir popular, la que por distintas razones creó lazos afectivos o económicos, comenzó a invertir en la ciudad, a generar plazas laborales, a frecuentar los espacios comunes que ofrece el pueblo. 


\section{REFERENCIAS BIBLIOGRÁFICAS}

DE VIRGILIO, M.; HEREDIA, M. (s/f.). "Clase social y territorio". Quid 16 Dossier (4-15), versión digital.

LEVINTON, N., (2007) Yacyretá: una nueva significación. La relación entre espacio y sociedad como consecuencia de la implantación de un megaproyecto. Entidad Binacional Yacyretá, Buenos Aires.

LÓPEZ BREARD, M. (2001) Ituzaingó. Un acercamiento a su pasado. Ed. Moglia, Corrientes.

LUCIANO, G. (2011) Breve historia de las ideas económicas. Imprenta de Arrechea, Posadas.

MATTEUCHI, S.; MORELLO, J. et ál. (2004) El Paraná Encajonado argentino-paraguayo. Mosaicos de paisaje y conservación regional. Ediciones FADU UNESCO, Buenos Aires.

PESCI, R. (2006) Vientos Verdes. Colección Sustentable N. ${ }^{\circ} 1$, Ed. Nobuko y Ed. CEPA, Buenos Aires.

RODRÍGUEZ MERKEL, G. (2014). "Qué es y qué no es segregación residencial. Contribuciones para un debate pendiente". Biblio 3W, Revista Bibliográfica de Geografía y Ciencias Sociales, Universidad de Barcelona, Serie documental de Geo Crítica. Cuadernos Críticos de Geografía Humana, Barcelona.

SÁNCHEZ NEGRETte, A.; VALENZUELA, M. V. (2011). "Transformaciones en el paisaje urbano -cultural y natural-- de Ituzaingó, Corrientes. Políticas urbanas para la valoración patrimonial y el desarrollo turístico en el contexto de las misiones jesuíticas". 1.er Congreso Latinoamericano de Estudios Urbanos, IPUR, FAU-UNNE, Resistencia. VALDÉS, E. (s/f). "Fragmentación y segregación urbana. Aportes teóricos para el análisis de casos en la ciudad de Córdoba". Disponible en: www. ffyh.unc.edu.ar/alfilo/anteriores/alfilo-18/pdf/valdes.pdf

VALENZUELA, M. V. (2009). "El Zanjón de Loreto. Su rol histórico y su estado actual". Jornadas de Ciencia y Técnica de la UNNE, Resistencia.

\section{FUENTES INÉDITAS}

BOFILL, C. (2011). "Ordenamiento territorial de los parques industriales en la provincia de Corrientes. Relevamiento ambiental". Informe final, Gobierno de la Provincia de Corrientes, Consejo Federal de Inversiones. CATULLO, M. (2014). "Análisis de una ciudad a partir de su proceso de relocalización. 40 años de historia: Federación/ Nueva Federación". XXXIV Encuentro de Geohistoria Regional, IIGHI-CONICET, Resistencia (en prensa).

SÁNCHEZ NEGRETTE, A.; GRANDO, J.; VALENZUELA, M. et ál. (2011). "Lineamientos y normativa para la puesta en valor del patrimonio arquitectónico y paisajístico de Ituzaingó, Corrientes, a los fines de su desarrollo turístico. Un modelo participativo". Informe final, Programa Universidad en el Medio, SGEU, UNNE. Tomo I.

SCORNIK, O.; GODOY, S. et ál. (2013). "Plan Estratégico de Ordenamiento Territorial del Municipio de Ituzaingó". Convenio Provincia de Corrientes CFI-UNNE, Facultad de Arquitectura y Urbanismo. Instituto de Planeamiento Urbano y Regional, IPUR-BAT, Resistencia.

VALENZUELA, M. V. (2014). "Las estancias de origen jesuíticoguaraní en Ituzaingó, Corrientes, como patrimonio del paisaje regional". XXXIV Encuentro de Geohistoria Regional, IIGHI-CONICET, Resistencia (en prensa).

\section{PÁGINAS WEB}

http://argentinainvestiga.edu.ar/diario virtual/1.0/listado/noticia. php?titulo=como_influye_yacyreta_en_las_plantas_acuaticas\&id=596\#. VYCEsPI Oko.

http://www.eby.org.ar/index.php/17-plan-de-terminacion-deyacyreta/235-yacyreta-programa-de-obras-electricas-poe. 